\title{
Concepções sobre práticas pedagógicas e ensino/aprendizagem sob a perspectiva de ciência, tecnologia e sociedade (CTS)
}

\author{
Tatiana Comiotto ${ }^{1}$ \\ Karoline dos Santos Tarnowski ${ }^{2}$ \\ Lucas Ribeiro de Laia $^{3}$ \\ Rubia Ana Millnitz ${ }^{4}$ \\ Thais Hardt ${ }^{5}$ \\ Lorena Silva de Andrade Dias ${ }^{6}$
}

\section{Resumo}

Pesquisas de cunho científico relacionadas ao campo educacional, propõem um aprimoramento e uma compreensão mais profunda dos educadores frente às suas próprias concepções de didática, ensino/ aprendizagem e prática pedagógica. Este artigo, referente a um estudo com discentes do curso de Licenciatura em Física da UDESC/Joinville, tem como objetivo identificar as concepções quanto a CTS (Ciência, Tecnologia e Sociedade), ensino/aprendizagem e prática pedagógica, a partir de um questionário aberto, realizado com 26 acadêmicos matriculados entre a $1^{\mathrm{a}}$ e a $8^{\mathrm{a}}$ fase do curso, presentes em sala de aula no dia de sua aplicação. Os resultados demonstraram que, os acadêmicos não possuem uma ampla visão em relação a CTS e que os mesmos procuram uma prática pedagógica menos apoiada em uma pedagogia tradicional e mais próxima ao cotidiano de seus alunos. As questões abordadas na pesquisa demostram concepções superficiais de alguns alunos ao longo do curso e a necessidade de reflexão sobre estas percepções.

Palavras-chave: Professores. Ensino/Aprendizagem. Prática pedagógica. CTS.

\begin{abstract}
Scientific research related to the educational field proposes an improvement and a deeper understanding of educators towards their own conceptions of didactics, teaching/learning and pedagogical practice. This article, referring to a study with undergraduate students of Physics from UDESC/Joinville, aims to identify the concepts regarding STS (Science, Technology and Society), teaching/learning and pedagogical practice, from an open questionnaire, carried out with 26 students enrolled between the 1st and the 8th phase of the course, present in the classroom on the day of its application. The results showed that the students do not have a broad vision regarding CTS and that they seek a pedagogical practice less supported in a traditional pedagogy and closer to the daily life of their students. The questions addressed in the research show superficial conceptions of some students along the course and the need to reflect on these perceptions.
\end{abstract}

Keywords: Teachers. Teaching/Learning. Pedagogical Practice. STS.

\footnotetext{
${ }^{1}$ Doutora em Educação Cientifica e Tecnológica pela Universidade Federal de Santa Catarina. É professora associada da Universidade do Estado de Santa Catarina (UDESC/CCT). E-mail: comiotto.tatiana@gmail.com

${ }^{2}$ Mestranda em Ensino de Ciências, Matemática e Tecnologias na Universidade do Estado de Santa Catarina (UDESC/CCT). E-mail: karol. tarnowski@hotmail.com

${ }^{3}$ Graduando do curso de Licenciatura em Química na Universidade do Estado de Santa Catarina (UDESC/CCT). E-mail: lucas.delaia@gmail.com ${ }^{4}$ Graduanda do curso de Licenciatura em Química, pela Universidade do Estado de Santa Catarina (UDESC/CCT). E-mail: rubiamillnitz@gmail. com

${ }^{5}$ Graduanda do curso de Licenciatura em Química, pela Universidade do Estado de Santa Catarina (UDESC/CCT). E-mail: thais.hardt@gmail. com

${ }^{6}$ Mestranda em Ensino de Ciências, Matemática e Tecnologias na Universidade do Estado de Santa Catarina (UDESC/CCT). E-mail: lorena. andradedias@gmail.com
} 
Introdução

A tríade Ciência, Tecnologia e Sociedade (CTS) iniciou-se a partir de meados do século XX como crítica à relação que versava somente sobre os conceitos de ciência e tecnologia (CT). Após as repercussões sobre o desenvolvimento técnico-científico e a visão de que este traria melhorias, a qualquer custo, ao bem-estar social em meio ao progresso econômico, surge uma apreensão de que os meios utilizados para dominar a natureza se voltem contra o homem. Buscou-se, então, a construção de uma visão de ciência e tecnologia com um olhar sobre as consequências e alcances na sociedade, nascendo assim a tríade CTS (AULER, 2002; BAZZO, 2002). De acordo com Cerezo (1999, p. 219), os estudos sobre CTS se tratam de,

Compreender a dimensão da ciência e da tecnologia, tanto do ponto de vista dos seus antecedentes sociais como das suas consequências na comunidade e no ambiente, isto é, no que diz respeito aos fatores de natureza social, políticos ou econômicos que modulam a mudança científico-tecnológica, quanto ao que diz respeito às repercussões éticas, ambientais ou culturais dessa mudança.

As considerações a respeito de CTS devem permitir transformações que estabeleçam novas relações sociais e, consequentemente, viabilizem a construção de uma visão de mundo integradora, sendo este um dos objetivos da educação (MENESTRINA, 2008). A visão integradora, segundo Menestrina (2008), é conectada a distintos aspectos, está atrelada às relações e por isso não há previsibilidade ou determinismo. É um sistema complexo, que procura ultrapassar as limitações entre as práticas, os conhecimentos e a existência. É formada por conhecimentos que foram agregados a partir de experiência, dados, saberes e arquétipos do pensamento, sendo difundidos pela tradição, pela educação e pela comunicação, além de serem socialmente organizados e partilhados entre diversos grupos.

Em termos de CTS, a visão de mundo integradora permite analisar a complexidade das relações entre os homens, em distintas escalas, assinalando um estilo epistemológico abrangente, que se baseia na construção e reconstrução constante da própria visão e das concepções delas decorrentes (MENESTRINA, 2008). Em relação à educação, a ligação estabelecida na CTS corresponde a "integração entre educação científica, tecnológica e social, em que os conteúdos científicos e tecnológicos são estudados juntamente com a discussão de seus aspectos históricos, éticos, políticos e sócio-econômicos (sic)" (SANTOS, 2002, p. 113). O enfoque CTS também é apropriado para "fomentar uma educação tecnocientífica dirigida à aprendizagem da participação, trazendo um novo significado para conceitos tão aceitos como alfabetização tecnocientífica, ciência para todos ou difusão da cultura científica" (GORDILLO; OSORIO, 2003, p. 166).

Nos cursos de graduação em licenciatura, têm-se como propósito a formação de professores capacitados para atuar no Ensino Fundamental e Médio. No entanto, percebe-se através da literatura e da prática pedagógica que, muitas vezes, esses cursos apresentam os conteúdos de maneira fragmentada e dogmática aos estudantes. Isso se apresenta quando questões sobre CTS são apenas discutidas, entre professores e acadêmicos, como necessárias, porém sem abordar estratégias que possam ser colocadas em prática no ambiente escolar. Dessa maneira, dependendo da forma como os licenciandos enxergam e se relacionam com mundo, isso pode influenciar o seu modo de entender e trabalhar a tríade CTS em sala de aula (ANGOTTI; AUTT, 2001). 
Partindo desse pressuposto, realizou-se uma pesquisa de campo com discentes do curso de Licenciatura em Física da UDESC/Joinville, com o objetivo identificar suas concepções referentes à CTS, ao ensino/aprendizagem e a prática pedagógica. Para isso, um questionário com perguntas abertas foi aplicado junto aos acadêmicos da primeira à oitava fase do curso. Esperava-se que os participantes já tivessem incorporado algumas concepções acerca desta temática por terem concluído o Ensino Médio - onde tais pressupostos teóricos deveriam ter sido construídos, de acordo com os Parâmetros Curriculares Nacionais (PCN) (BRASIL, 2000) - e, também, por cursarem na segunda fase da graduação disciplinas específicas que, conforme suas ementas, discutem este conteúdo.

\section{Metodologia e instrumentos de pesquisa}

Com o objetivo de identificar as concepções dos acadêmicos do curso de Licenciatura em Física sobre CTS, ensino/aprendizagem e prática pedagógica, uma pesquisa participativa foi realizada com os acadêmicos matriculados nesta graduação, no ano de 2013. A pesquisa participativa é um modelo que representa a diversidade dos contextos sociais. Segundo as ideias de Moreira (2011, p. 98), “na pesquisa participativa não há receitas nem ortodoxias metodológicas: as questões e os métodos de trabalho devem fluir dos sujeitos envolvidos e de seu contexto".

Para isso, um questionário contendo seis perguntas foi aplicado junto aos 26 alunos, de diferentes fases do curso de Física, presentes em sala de aula no dia de sua realização. A apreciação das concepções se deu a partir da análise das respostas às seguintes questões:

1. É possível estabelecer alguma relação entre o enfoque CTS, prática pedagógica e ensino? Justifique sua resposta.

2. O que você mudaria na prática pedagógica? Quais os empecilhos para que tais mudanças ocorram?

3. Quais os limites e possibilidades da prática pedagógica?

A disciplina de 'Ciência, Sociedade e Tecnologia', integrante do grupo de disciplinas optativas de Licenciatura em Física, recebe matricula de alunos de todas as fases do curso, isto é, da $1^{\mathrm{a}}$ à $8^{\mathrm{a}}$ fase da graduação. A Tabela 1 apresenta a distribuição de acadêmicos por fase, que participaram da pesquisa.

Tabela 1- Distribuição de acadêmicos por fases

\begin{tabular}{|c|c|}
\hline FASE & ALUNOS PARTICIPANTES \\
\hline $1^{\text {a }}$ Fase & 4 \\
\hline $2^{\text {a }}$ Fase & 5 \\
\hline $3^{\text {a }}$ Fase & 2 \\
\hline $4^{\text {a }}$ Fase & 3 \\
\hline $5^{\text {a Fase }}$ & 3 \\
\hline $6^{\text {a Fase }}$ & 1 \\
\hline $7^{\text {a Fase }}$ & 4 \\
\hline $8^{\text {a Fase }}$ & 4 \\
\hline Total & 26 alunos \\
\hline
\end{tabular}

Fonte: Os autores (2015) 
O questionário aplicado foi construído com uma intencionalidade pedagógica ${ }^{7}$, contendo questões abertas. Inicialmente, realizou-se um estudo piloto a fim de testa-lo, em 2013. Em seguida, o projeto foi enviado e aprovado pelo Comitê de Ética da UDESC. A coleta de dados ocorreu entre agosto e dezembro, do mesmo ano, realizada por acadêmicos do curso de Licenciatura em Química, da UDESC/Joinville, matriculados na disciplina de 'CTS - Ciência, Tecnologia e Sociedade'. O tratamento dos dados foi realizado de forma qualitativa e as respostas discursivas interpretadas através da Análise de Conteúdo proposto por Bardin (1977).

A etapa qualitativa se caracteriza pela compreensão das características e significados apresentados pelos entrevistados. De acordo com Pinheiro (2010), há uma relação dinâmica entre o sujeito de análise e o mundo real, um vínculo indissociável, que não pode ser traduzido em números. Segundo Augusto et al. (2013, p. 747), é envolvido na pesquisa qualitativa uma abordagem onde os pesquisadores estudam seus objetos de análise dentro de seus contextos naturais, buscando compreende-los conforme o significado que lhes é atribuído.

\section{Análise e discussão de dados}

AAnálise de Conteúdo, proposta por Bardin (1977), é um procedimento empregado em pesquisas qualitativas com o intuito de compreender os preceitos e aspectos apresentados pelo estudo. Nas palavras de Bardin (1977, p.42), a

\footnotetext{
Análise de Conteúdo é um conjunto de técnicas de análise de comunicações visando obter, por procedimentos sistemáticos e objetivos de descrição de conteúdo das mensagens, indicadores (quantitativos ou não) que permitam a inferência de conhecimentos relativos às condições de produção/recepção destas mensagens.
}

Assim, a Análise de Conteúdo foi estruturada por três etapas distintas (BARDIN, 1977):

- Pré-análise: escolha dos documentos a serem previamente analisados (questionários);

- Exploração do material: utilização da categorização de temáticas adequadas à análise;

- Tratamento dos resultados: realização das interpretações e reflexões sobre a temática abordada, fundamentada nos materiais coletados.

Esse método permitiu a análise de motivações, atitudes, valores, crenças, tendências ou concepções dos acadêmicos pesquisados. As categorias de análise foram escolhidas a posteriori, a partir das respostas dos acadêmicos de licenciatura em Física, e são: concepções de ensino/aprendizagem e prática na perspectiva CTS; o estudante e o sentido atribuído à escola e; o ensino de CTS na formação de futuros professores - uma concepção (possivelmente) fragmentada.

\footnotetext{
Questionário construído com a finalidade didática de identificar, ou não, na prática elementos essenciais contidos na teoria. Serve de reflexão e tomada de posicionamentos (NEGRI, 2008).
} 
Concepções de ensino/aprendizagem e prática pedagógica na perspectiva CTS

As respostas mais destacadas pelos discentes, quando abordavam questões de ensino, aprendizagem e a prática pedagógica, foram a relação do professor como figura central de mudanças nas práticas pedagógicas. Segundo Togatlian (2008), as práticas pedagógicas que o professor adota em sala de aula interferem nos aspectos cognitivos e afetivos do estudante. O conceito de afetividade enfatiza a relação professor-estudante e as condições de ensino às quais os alunos são expostos. Nesta perspectiva, para alguns acadêmicos entrevistados, o professor é a figura principal no processo de ensino/aprendizagem.

Em relação à possibilidade de se "É possível estabelecer alguma relação entre o enfoque CTS, prática pedagógica e ensino? Justifique sua resposta", os acadêmicos relataram que isso depende do professor e que, na maioria das vezes, isso não ocorre. Na afirmação dos acadêmicos da $5^{\mathrm{a}}$ e $8^{\mathrm{a}}$ fase, por exemplo ${ }^{8}$,
A1 - É possível sim, basta o professor realizar uma prática de ensino em que aborde o CTS durante sua aula, não sendo apenas o mesmo cuspe-giz de sempre, contextualizando os assuntos da disciplina com a vida prática do estudante. (Grifo nosso)
A2 - O enfoque CTS é importante para fazer o conhecimento transcender a sala de aula e ter alguma relação direta com o cotidiano dos acadêmicos, o que promove uma aprendizagem mais significativa. Porém, não é o que acontece. (Grifo nosso)

Ainda nas respostas foram enfatizados a desmotivação, a falta de capacitação do docente e o desinteresse desses profissionais. De acordo com acadêmicos da $7^{\mathrm{a}}$ e $1^{\mathrm{a}}$ fase, respectivamente,
A3 - Seria interessante se os professores se sentissem motivados a criar um ambiente encorajador em
sala de aula, que levassem os acadêmicos a argumentar e expor suas dúvidas e realidades. Acredito que o que dificulta esta prática é a desmotivação e a falta de carga horária para o preparo das aulas. Além do salário, é claro.
A4 - A mente fechada de velhos professores, a má formação, desinteresse dos mesmos e a má aplicação do conteúdo contribuem para uma prática pedagógica mais voltada ao método tradicional.

Os entraves relatados pelos acadêmicos quanto à prática pedagógica dos docentes são afins às ideias de Sanchotene e Molina (2010), que afirmam que a organização da comunidade escolar está diretamente ligada às práticas pedagógicas que os professores adotam e aos assuntos trabalhados em sala. Gatti (2003, p. 195) completa que,

\footnotetext{
Há também que se considerar o papel de eventos mais amplos, sejam sociais, políticos, econômicos ou culturais, com seus determinantes que perpassam a vida grupal ou comunitária. Sabemos que a interação desses fatores molda as concepções sobre educação, ensino, papel profissional, e as práticas a elas ligadas, concepções e práticas estas que, por sua vez, são estruturalmente delimitadas pela maneira que as pessoas se veem, como estruturam suas representações, como se descrevem, como veem os outros e a sociedade à qual pertencem.
}

Já para a pergunta "Quais são os limites e possibilidades da sua prática pedagógica?", prevaleceram as respostas relacionadas aos limites. Foram citadas a falta de recursos, a resistência de professores ao uso de novas

\footnotetext{
${ }^{8}$ As transcrições realizadas, ao longo do artigo, encontram-se na forma literal, ou seja, exatamente como os acadêmicos mencionaram.
} 
tecnologias, a desvalorização profissional, a infraestrutura escolar, provas como vestibulares e ENEM $^{9}$ e os sistemas econômico, político e social. Conforme relatado,
A11 - É preciso maior aceitação de professores às tecnologias, por exemplo. (Estudante da $2^{\mathrm{a}}$ fase). (Grifo nosso)
A12 - Os limites são os recursos disponibilizados ao professor. As possibilidades seriam suprir esses recursos do professor e diminuir o número de acadêmicos em sala. (Estudante da $3^{\mathrm{a}}$ fase). (Grifo nosso)

Segundo Sampaio e Leite (2001), o professor precisa manter-se constantemente atualizado, procurando se adaptar ao novo perfil da sociedade tecnológica. Atualmente, a sociedade está exposta à numerosas variedades tecnológicas, influenciando a vida cotidiana dos acadêmicos. Deste modo, pode-se proporcionar a formação crítica e cidadã, possibilitando dominar, compreender e utilizar esses avanços em prol de família, da sociedade e de si mesmo.

Ainda sobre limites e possibilidades na prática docente, notou-se nas respostas dos acadêmicos a necessidade de reforçar os conceitos a respeito de abordagens CTS e práticas pedagógicas no decorrer da graduação. À essa questão um estudante da $1^{\text {a }}$ fase respondeu: "Não há limites; possível tornar cada vez mais prazeroso o estudo". Já outro aluno, da $6^{\mathrm{a}}$ fase, afirmou: "Creio que a melhor prática seja um bom professor, quadro, giz e um bom $\underline{\text { livro }}$. . Ainda, um acadêmico da $7^{\mathrm{a}}$ fase disse: “Os limites quem impõe normalmente é a própria direção e as possibilidades são infinitas, só dependem da motivação do professor ’”. (Todos grifos nossos).

Uma das respostas aborda como limite a direção da escola, enquanto outra afirma não haver limites. Dessa maneira, esses acadêmicos das $1^{\mathrm{a}}$ e $7^{\mathrm{a}}$ fases não levaram em consideração fatores sociais, políticos, econômicos e culturais exteriores e interiores à escola, os quais estão relacionados à CTS, de acordo com Ramos, Pinto e Vianna (2009). Além disso, ainda sobre a resposta do estudante da $7^{\mathrm{a}}$ fase, este mostrou sua concepção de que as possibilidades dependem unicamente da motivação do professor, não considerando a motivação e participação dos acadêmicos no processo de aprendizagem, como Santos (2002) defende ser necessária.

\section{0 estudante e 0 sentido atribuído à escola}

Segundo Carletto (2011), a proposta educativa não deveria ter o intuito de formar um sujeito neutro, ou seja, que não se posiciona frente às discussões, passivo ou como mero ouvinte. Nesta perspectiva, um estudante da $3^{\mathrm{a}}$ fase afirmou que os acadêmicos são "Receptores e passivos perante o conhecimento". Nas palavras de Menezes e Santiago (2014), é importante proporcionar oportunidades aos discentes à compreensão de suas relações com o ambiente e a realidade. Dessa forma, há um estímulo em querer transformar a realidade vigente, contribuindo para um mundo mais crítico a fim de se extinguir a passividade e a neutralidade no âmbito escolar e, consequentemente, na sociedade.

O estudante passivo, que Paulo Freire problematiza, encontra-se nessa situação devido a diferentes fatores, entre eles às influências da Pedagogia Tradicional, cujas características foram inicialmente observadas no século XVI (LOBO NETO, 2010). Nessa concepção pedagógica, o professor é tido como detentor do conhecimento e o centro do processo educativo, e o estudante é simplesmente o receptor. Por conta dessa característica, historicamente 
veio sendo atribuído aos alunos o papel de meros ouvintes dos conhecimentos adquiridos pela humanidade, o que se reflete até a atualidade (SAVIANI, 2005).

Tal concepção pedagógica tem contribuído para a insatisfação por parte dos estudantes quanto à escola. Isso porque os conteúdos trabalhados em sala de aula têm como foco subsidiar assuntos que, futuramente, serão cobrados no vestibular ou num curso de graduação. Dessa forma, os estudantes que se encontram no Ensino Fundamental ou Médio podem não ver sentido e, até mesmo, utilidade para grande parte dos assuntos ensinados, já que as problemáticas da vida em sociedade não são abordadas.

Nessa perspectiva, os acadêmicos do curso de Licenciatura em Física, quando questionados sobre "O que você mudaria em sua prática pedagógica? Quais os empecilhos para que tais mudanças ocorram?", responderam que trariam mais aulas práticas. De acordo com Almeida et al. (2008) a aula prática é um modo eficaz de ensinar e ampliar a compreensão dos conteúdos, auxiliando na aprendizagem. As aulas experimentais favorecem o entendimento de ciência e contribuem para o interesse da mesma. Nesse sentido, as respostas mostram o anseio dos acadêmicos por aulas que tenham mais relação com suas vidas e o mundo, ou seja, que sejam de maneira mais contextualizada.

O desinteresse por parte dos acadêmicos também foi enfatizado por discentes de todas as fases,

$$
\begin{aligned}
& \text { A9 - Creio que há uma grande defasagem nos acadêmicos nos dias de hoje. Muito desestimulados, } \\
& \text { falta responsabilidade e foco. Prefiro não opinar mais. (Estudante da } 6^{\mathrm{a}} \text { fase). (Grifo nosso) } \\
& \text { A10 - Alienados em um mundo com tanta tecnologia acessível. Ansiosos e ao mesmo tempo } \\
& \text { desinteressados. Na verdade, é um grande misto de personalidades e comportamentos. (Estudante } \\
& \text { da } 7^{\mathrm{a}} \text { fase). (Grifo nosso) }
\end{aligned}
$$

Acredita-se que isso deva ser constantemente analisado e questionado, principalmente no que tange aos fatores que levam os acadêmicos a se interessar mais pelo ambiente exterior do que pela sala de aula. Conforme o PCN (BRASIL, 2000), a junção de diferentes saberes pode criar as condições necessárias para que haja uma aprendizagem motivadora, onde se deve estimular todos às atividades e procedimentos que oportunize ao estudante reconstruir ou "reinventar" o conhecimento didaticamente exposto em sala de aula, citando a experimentação como exemplo. Neste sentido, o distanciamento entre os conteúdos programáticos e a experiência dos estudantes, sem dúvida, responde pelo desinteresse dos alunos e até mesmo pelo seu abandono às escolas.

Além disso, os acadêmicos participantes destacaram como empecilhos a falta de aproximação da escola com a vida cotidiana e, também, a questão salarial,

$$
\begin{aligned}
& \text { A7 - Devia se deixar o ensino tradicional, para práticas que melhor ajudem no aprendizado do } \\
& \text { estudante. A aula desta é mais trabalhosa para se preparar (Estudante da } 3^{\text {a }} \text { fase). } \\
& \text { A8 - O uso de tecnologia em sala de aula, uma maior aproximação do conteúdo ensinado na escola } \\
& \text { e a vida do estudante, etc. Salário desmotivador, maior empecilho de todos! (Estudante da } 5^{\text {a fase). }} \\
& \text { (Grifo nosso) }
\end{aligned}
$$

Essas críticas foram mais frequentes nas respostas dos alunos matriculados a partir da $3^{\mathrm{a}}$ fase do curso. Acredita-se que isso seja devido, principalmente, à inserção de disciplinas da área de educação - que ocorrem a partir do $3^{\circ}$ semestre da graduação - como, por exemplo, "Prática de Ensino de Física", onde são avaliados os métodos de ensino, análises dos materiais didáticos e também o planejamento de aulas. 
0 ensino de CTS na formação de futuros professores - uma concepção (possivelmente) fragmentada

Dependendo do que é trabalhado em sala de aula, quando não se abordam questões científicas que influenciam a realidade da sociedade, por exemplo, ou deixam de serem problematizadas as implicações tecnológicas advindas da ciência na sociedade, os acadêmicos podem vir a apresentar uma visão fragmentada e não integradora de CTS.

Os cursos de graduação em licenciatura têm por objetivo a formação de professores capacitados através da passagem destes profissionais por disciplinas de cunho específico e educacional. Neste quesito as universidades podem deixar de lado o ensino da ciência, tecnologia e sociedade como uma tríade inseparável.

Segundo Bazzo (2002), CTS pode ser compreendida como a relação direta entre "C e T", através de suas consequências e alcances dentro da "S". Bazzo e Vieira (2007, p. 2) afirmam a importância dos estudos nessa área:

A inserção de discussões sobre controvérsias científicas tem o potencial de estimular o educando a sentir-se parte da sociedade em que vive, a se interessar pelos seus problemas e a participar das discussões decorrentes das interações ciência/tecnologia/sociedade.

$\mathrm{Na}$ análise dos resultados desta pesquisa, é importante ressaltar que a matriz curricular do curso de Licenciatura em Física não possui uma disciplina específica em CTS. No entanto, tais abordagens são realizadas em Instrumentação para o Ensino de Física I, na $5^{\text {a }}$ fase. Este método de abordagem, segundo Carletto (2011), é chamada de "Ciência e Tecnologia através de CTS", onde ocorre a introdução de disciplinas isoladas ou de cunho científico. Trata-se da abordagem de CTS por meio de problemáticas triviais e que se vinculem com os futuros papéis dos estudantes dentro da sociedade, mediante aos conhecimentos científicos e tecnológicos.

Outros métodos de abordagem relativos à CTS são, de acordo com Ritter e Maldaner (2014),

- CTS puro: é o estudo de CTS em que o conteúdo científico passa a ser subordinado e as questões relativas à temática são mostradas de maneira histórica, do passado até a situação vigente;

- $\quad$ Enxerto de CTS: introduzir nas disciplinas de ciências, e não somente em uma disciplina isolada, os temas relativos à CTS.

As implicações de uma abordagem não significativa em CTS na formação de professores têm consequências graves. Carletto (2011) afirma que a formação destes profissionais deve ocorrer de maneira explícita à abordagem CTS, dando oportunidades para refletirem sobre todas as questões que o envolvem, já que uma abordagem implícita não o prepararia para uma formação efetiva de sua profissão. Menestrina (2008) diz que a formação acadêmica deve permitir ao estudante a capacidade de reconhecer as questões pertinentes ao seu entorno, avaliando diferentes posições em relação a ele e, de forma consciente, atuar junto à sociedade. Ainda para Menestrina (2008), a Educação em CTS tem como finalidade formar um cidadão crítico e consciente, que construa novas tecnologias e conhecimentos científicos, implicando na formação de profissionais qualificados que melhorem a qualidade de vida do homem e da sociedade.

Oliveira (1999) acentua que o desenvolvimento tecnológico, em extrema escala, facilitou a troca de informações e até mesmo uma enculturação. Como, por exemplo, podem ser citados os meios de comunicações novos e diversificados que atingem cada vez mais pessoas e originam essa cultura em massa. Tal cultura está relacionada aos bens materiais, valores, crenças, conhecimento, interesses, enfim, a um conjunto de regras que 
conduzem e influenciam a vida em sociedade. Sobre as influências dessas regras, segundo Morais (2012), a propaganda nos dias de hoje retira cada vez mais a liberdade, tornando nossa sociedade tecnológica seu próprio reflexo. Ou seja, há uma modelação conforme a sociedade e, que devido à aceitação passiva de dogmas impostos por técnicas, ameaça a humanidade a perder as rédeas de sua própria história.

Percebe-se então, conforme Menestrina (2008), que se deve formar profissionais que não se satisfaçam somente com o mercado de trabalho - pois isto contribuiria apenas para mais problemas sociais -, mas que executem ações que beneficiem a sociedade no qual interagem e vivem.

\section{Considerações finais}

Em relação às concepções dos discentes do curso de Licenciatura em Física da UDESC/Joinville, acerca de práticas pedagógicas, ensino/aprendizagem e CTS, esperava-se que esses acadêmicos tivessem internalizado concepções mais integradoras sobre tais temas, isso porque os mesmos já são formados no Ensino Médio onde, principalmente no caso de CTS, tais concepções deveriam ter sido formadas (pois as aulas são, ou melhor, deveriam ser ministradas de acordo com os Parâmetros Curriculares Nacionais) e, ainda, por estarem num curso de licenciatura que aborda essas questões em diferentes disciplinas. Assim sendo, por esse motivo esperavase que os discentes de maneira geral tivessem apresentado uma visão mais ampla nesse quesito. No entanto, é reconhecido que $34 \%$ e $54 \%$ dos acadêmicos ainda não haviam cursado as disciplinas de Prática de Ensino de Física e Instrumentação para o Ensino de Física I, respectivamente, onde as questões relativas ao ensino de CTS são mais trabalhadas, trazendo uma compreensão mais ampla a respeito dessa temática. Apesar disso, de modo geral, foi observado entre os discentes de todas as fases a necessidade da aproximação do que é trabalhado na escola com a vida dos acadêmicos, os reais objetivo e função da escola e o desinteresse tanto de professores quanto dos acadêmicos. A partir dessas respostas pode-se constatar o desejo dos acadêmicos por uma educação diferente da qual se aplica hoje. Educação esta que, na opinião dos autores desse artigo, deveria priorizar e problematizar as questões CTS no âmbito escolar, pois elas, em muitos casos, podem influenciar o modo de pensar e analisar criticamente questões da ciência e tecnologia num âmbito social, contribuindo de maneira significativa para a formação de acadêmicos e cidadãos mais críticos.

\section{Referências}

ALMEIDA, E. B. S; DA SILVA, M. F. C; LIMA, J. P; SILVA, M. L; BRAGA, C. F; BRASILINO, M. G. A. Contextualização do Ensino de Química: Motivando Estudantes de Ensino Médio. Disponível em: http://www.prac.ufpb.br/anais/xenex_xienid/x_enex/ANAIS/Area4/4CCENDQPEX01. pdf $>$. 2008. Acesso em 06/04/16.

ANGOTTI, J. A. P. e AUTT, M. A. Ciência e tecnologia: implicações sociais e o papel da educação. Ciência \& Educação. Vol. 7. Nº1. 2001. 
AUGUSTO, Cleiciele Albuquerque et al. Pesquisa Qualitativa: rigor metodológico no tratamento da teoria dos custos de transação em artigos apresentados nos congressos da Sober (2007-2011). Rev. Econ. Sociol. Rural. vol.51. no.4. Brasília: Oct./Dec. 2013.

AULER, D. Interações entre ciência-tecnologia-sociedade no contexto da formação de professores de ciências. 2002. 248f. Tese (Doutorado) - Centro de Ciências da Educação, Programa de Pós-Graduação em Educação. luniversidade Federal de Santa Catarina, Florianópolis. 2002.

BARDIN, L. Análise de conteúdo. Lisboa: Edições 70. 1977.

BAZZO, V. A. A pertinência de abordagens CTS na educação tecnológica. Revista Iberoamericana de educação, n. 28. 2002.

BAZZO, W. A; VIEIRA, K. R. C. F. Discussão acerca do aquecimento global: Uma proposta CTS para abordar esse tema controverso em sala de aula. Florianópolis, v. 1, n. especial, nov. 2007.

BRASIL. Parâmetros Curriculares Nacionais Ensino Médio 2000. Disponível em: $<$ http://portal. mec.gov.br/seb/arquivos/pdf/blegais.pdf $>$ Acesso em 05/04/16

CARLETTO, M. R. Avaliação de impacto tecnológico: Reflexões, fundamentos e práticas. 1 ed. Curitiba: Ed. UTFPR. 2011.

CEREZO, J.A.L. Los estudios de ciencia, tecnología y sociedad. Revista Ibero-Americana de Educação, n. 20, 1999.

GATTI, B. Formação continuada de professores: A questão psicossocial. Cadernos de Pesquisa. n. 119. p. 191-214. 2003.

GORDILLO, M.M; OSORIO, C. Educar para participar en ciencia y tecnología. Un proyecto para la difusión de la cultura científica. Revista Ibero-Americana de Educação, n. 32, 2003.

LOBO NETO, F. J. S. L. A Pedagogia Tradicional: Marcos de Sua Manifestação e Consolidação. Disponível em <http://www.floboneto.pro.br/>. 2010. Acesso em: 15 abr. 2015.

MENESTRINA, T. C. Concepção de ciência, tecnologia e sociedade na formação de engenheiros: um estudo de caso das engenharias da UDESC Joinville. Florianópolis, 2008. 228f. Tese (Doutorado em Educação Científica e Tecnológica) - Programa de Pós-graduação em educação científica e tecnológica, Universidade Federal de Santa Catarina, Florianópolis, 2008.

MENEZES, M. G; SANTIAGO, M. E. Contribuição do pensamento de Paulo Freire para o paradigma curricular crítico emancipatório. Pró-Posições, v. 25, n. 3, p. 45-62, set./dez. 2014.

MORAIS, R. Filosofia da ciência e da tecnologia: introdução metodológica e crítica. 10 ed. Campinas: Papirus. 2012.

MOREIRA, M. A. Metodologias de Pesquisa em Ensino. 1 ed. São Paulo: Livraria da Física. 2011. 
NEGRI, P. S. Comunicação Didática: A Intencionalidade Pedagógica como Estratégia de Ensino: Módulo I. Laboratório de Tecnologia Educacional da Universidade Estadual de Londrina - Labted. 2008.

OLIVEIRA, P. S. Introdução à sociologia. 22 ed. São Paulo: Editora Ática. 1999.

PINHEIRO, J. M. S. Da iniciação científica ao TCC. Rio de Janeiro: Editora Ciência Moderna. 2010

RAMOS, E. R.; PINTO, S. P. e VIANNA, D. M. Ciência, Tecnologia e Sociedade no contexto da sala de aula. Instituto de Física. Universidade Federal do Rio de Janeiro. 2009.

RITTER, Jaqueline. MALDANER, Otavio Aluisio. CTS na situação de estudo: desenvolvimento de currículo e formação de professores. Revista Praxis \& Saber. Vol. 6. Núm. 11. Jan./Jun. 2015.

SAMPAIO, M. N.; LEITE, L. S. Alfabetização Tecnológica do Professor. 2 ed. Petrópolis: Vozes. 2001.

SANCHOTENE, M. S. U.; MOLINA NETO, V. Práticas pedagógicas: Entre a produção e a reflexão. Rev. Bras. Cienc. Esporte. Campinas, v. 31, n. 3, p. 57-59. 2010.

SANTOS, J. C. A participação ativa e efetiva do estudante no processo ensino-aprendizagem como condição fundamental para a construção do conhecimento. Dissertação. UFRGS. Porto Alegre. 2002.

SAVIANI, D. As concepções pedagógicas na história da educação brasileira. Campinas: Histedbr. 2005.

TOGATLIAN, M. A. Resenha: Relação professor-estudante e práticas pedagógicas. Rio de Janeiro, v. 24. n 3, p. 387-388. 2008.

Recebido em: 17/01/2019

Aprovado em: 29/04/2019 